\title{
The Influence of Composite Lay-Up on the Stability of a Structure with Closed Section
}

\author{
Patryk Różyło ${ }^{1 *}$, Hubert Dębski ${ }^{1}$ \\ 1 Mechanical Engineering Faculty, Lublin University of Technology, ul. Nadbystrzycka 36, 20-618 Lublin, Poland \\ * Corresponding author's e-mail: p.rozylo@pollub.pl
}

\begin{abstract}
This paper presents a study on the stability of a composite structure with a closed section. The research was carried out solely based on numerical simulations using the finite element method. ABAQUS software was used to conduct numerical simulations, which allowed to determine the values of critical loads, as well as the corresponding forms of buckling. As part of the research, the influence of composite material arrangement of layers on the stability of the structure was analyzed. The study was conducted on a composite material, which is a carbon-epoxy composite (CFRP). The obtained research results will be verified in subsequent studies by the results of experimental tests.
\end{abstract}

Keywords: buckling, composite closed-section profiles, critical load, FEM.

\section{INTRODUCTION}

The stability of thin-walled composite profiles, is an ongoing research issue, especially from an engineering perspective. Stability, as the ability of a mechanical system to independently return to the equilibrium state, from which it was knocked out, e.g. as a result of external loads, is a very desirable property of construction [1-6]. This type of characteristic are characterized by thin-walled structures, in recent times, especially made of composite materials, such as carbon-epoxy composite. Due to the fact that thin-walled structures are used as load-carrying profiles, such structures often undergo a phenomenon commonly referred to as loss of stability (which is commonly known as buckling) [7-10]. This phenomenon occurs due to axial or non-axial compression of thin-walled structures, which results in the aforementioned buckling. In the initial stage of axial compression, a thin-walled structure is subjected to a state in which its walls are purely in compression (membrane state). In the next stage, there is a state in which there is a loss of stability, where the form of deformation of the structure changes - the critical state. The last post-buckling state is a state in which the increase in load is accompanied by a simultaneous increase in deflection of the structure [11-16].

In this paper, special consideration will be given mainly to the phenomenon of loss of stability of composite structure with closed cross-section. In the literature, there are already many scientific studies on the issue of loss of stability of thinwalled composite structures, however, the vast majority of studies concern structures with open cross-sections [17-21]. Profiles with open crosssections are more prone to loss of stability, mainly due to lower structural stiffness than would be the case with closed profiles. A number of already conducted research on the stability of composite structures with open sections provided important information on the discussed issue. Therefore, it is important to conduct research on composite profiles with closed sections, because this type of structure has not yet been thoroughly analyzed in terms of buckling phenomenon [22, 23].

The figure presented below shows the theoretical assumption according to which the ideal structure (numerical simulations - FEM) and the actual structure (experimental testing - EXP) behaves. In case of numerical simulations, it is 


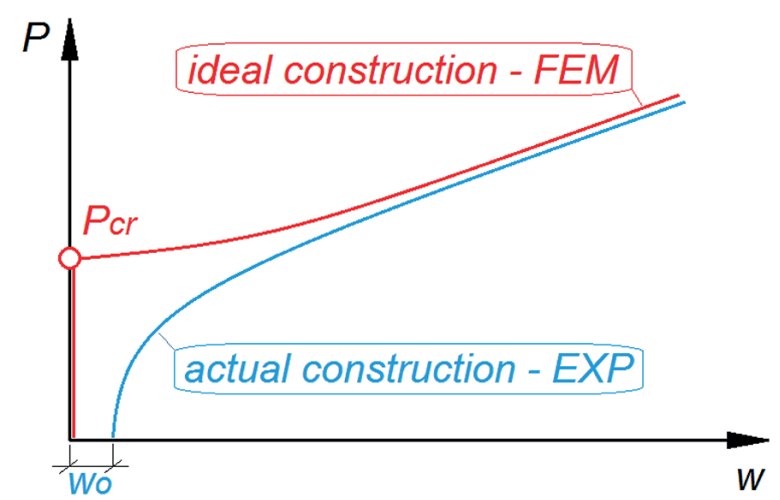

Fig. 1. Critical state

possible to determine the bifurcation (critical) load $\left(\mathrm{P}_{\mathrm{cr}}\right)$. In case of the actual construction, predeflection $\left(\mathrm{w}_{\mathrm{o}}\right)$ occurs, while the determination of the critical loads is based on approximation methods, which will be the subject of further study.

The reason for conducting this research is primarily due to the fact that the topic of stability, and load-carrying capacity of thin-walled structures, made of composite materials is still a current engineering issue, which is important especially from the point of view of behavior of the structure in the critical state.

\section{THE SUBJECT OF STUDY}

The subject of the study are thin-walled composite columns, made of carbon-epoxy composite (CFRP). The material (mechanical and strength) properties of the composite structure, are presented in Table $1[12,13]$.

In this paper, a composite structure with a square cross-section, subjected to axial compression, is numerically analyzed. The geometrical parameters of the test specimen are shown as an example in Figure 2.

The structure made of composite material consisted of 8 layers (each layer had a thickness of 0.1 $\mathrm{mm}$ ) with their symmetrical arrangement with respect to the central plane of the laminate. In this study, four different configurations of composite

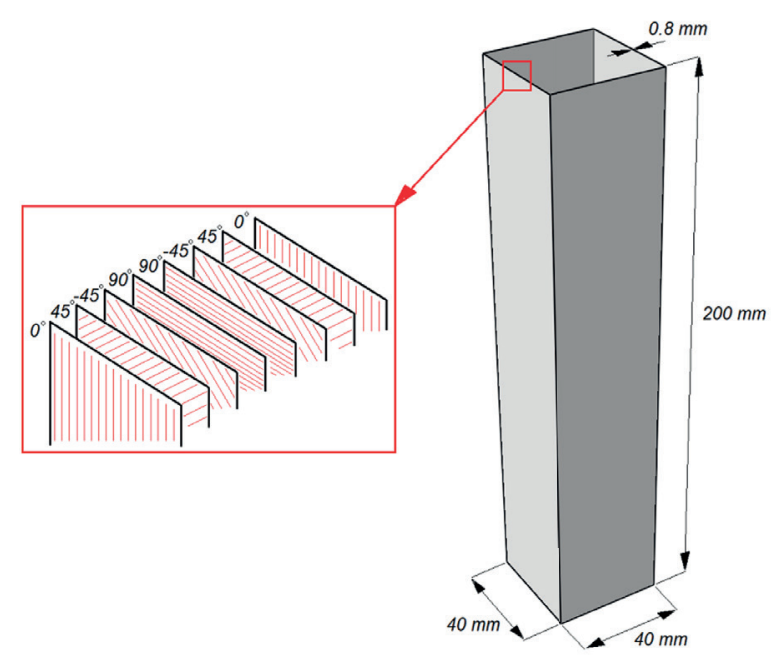

Fig. 2. Geometrical parameters of the specimen

material layers were considered, which were designated P1 - $[0 / 45 /-45 / 90]_{\mathrm{s}}, \mathrm{P} 2$ - [0/90/0/90 $]_{\mathrm{s}}, \mathrm{P} 3$ $[45 /-45 / 90 / 0]_{\mathrm{S}}$ and $\mathrm{P} 4-[90 /-45 / 45 / 0]_{\mathrm{S}}$, respectively.

\section{NUMERICAL SIMULATIONS}

The study was conducted using numerical simulations based on the finite element method (FEM). Numerical simulations were carried out on the basis of the solution of the linear stability problem of the structure, based on the solution of the linear eigenproblem, using the minimum potential energy criterion. The stability problem in mathematical terms could be determined by the following relation:

$$
K+\lambda H=0
$$

where: $K$ - stiffness matrix, $H$ - geometric stiffness matrix, $\lambda$ - critical variable (in analyzed case - bifurcation load).

In the conducted numerical research, a few assumptions were adopted, which allowed to determine the phenomenon of loss of stability (buckling) of the structure. As part of the research, a numerical model was prepared, consisting of both a thin-walled composite structure and two plates,

Table 1. Material properties of the composite (carbon-epoxy laminate) material

\begin{tabular}{|c|c|c|c|c|c|c|}
\hline \multicolumn{4}{|c|}{ Mechanical parameters } & \multicolumn{3}{|c|}{ Strength parameters } \\
\hline$E_{1}$ & \multirow{2}{*}{ Young's modulus } & \multirow{3}{*}{ [MPa] } & 130710 & $F_{\mathrm{T} 1}\left(0^{\circ}\right)$ - Tensile & \multirow{5}{*}{$\begin{array}{c}\text { Strength } \\
\text { [MPa] }\end{array}$} & 1867.2 \\
\hline$E_{2}$ & & & 6360 & $F_{\mathrm{C} 1}\left(0^{\circ}\right)$ - Compressive & & 1531 \\
\hline \multicolumn{2}{|c|}{$G_{12}-$ Kirchhoff modulus } & & 4180 & $F_{\mathrm{T} 2}\left(90^{\circ}\right)$ - Tensile & & 25.97 \\
\hline \multicolumn{3}{|c|}{$\mathrm{v}_{12}$ - Poisson's coefficient [-] } & 0.32 & $F_{\mathrm{C} 2}\left(90^{\circ}\right)$ - Compressive & & 214 \\
\hline \multicolumn{3}{|c|}{-} & - & $F_{12}-$ Shear & & 100.15 \\
\hline
\end{tabular}




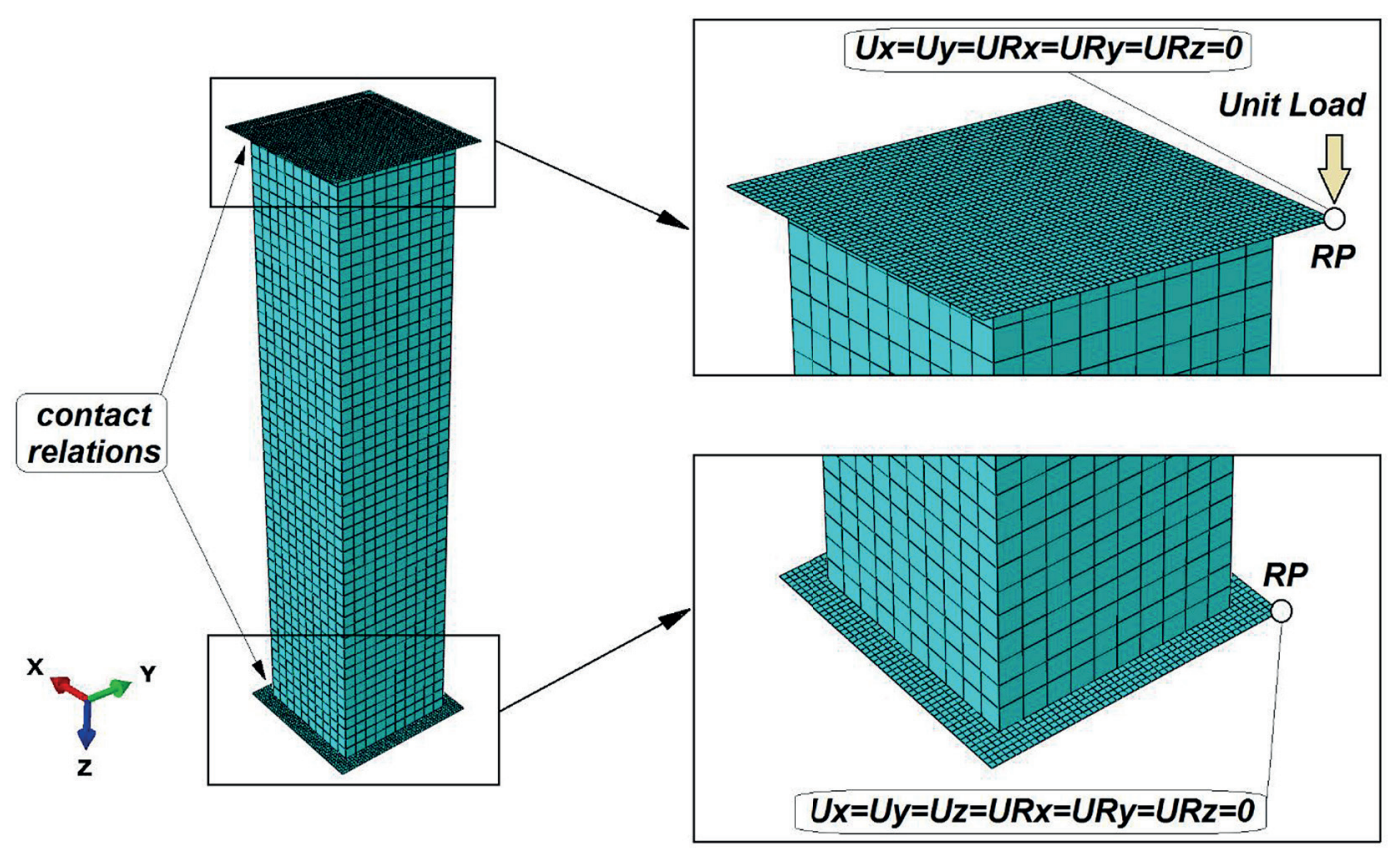

Fig. 3. Boundary condition

which are the supports of the structure. One of the plates was fully fixed, while the other plate had the only ability to move in the compression direction of the composite structure. Between the composite structure and the plates, contact properties in the tangential and normal directions were included (with a friction coefficient of 0.2). The boundary conditions were defined at special reference points (RP) which were coupled to the elements representing the supports. The boundary conditions are presented in Figure 3.

The discrete model was prepared based on the use of shell finite elements. For the composite structure, S4R type linear shape function elements with reduced integration were used, having 4 computational nodes per finite element, where each node contains 6 degrees of freedom ( 3 translational and 3 rotational). For non-deformable supports, shell finite elements of type R3D4 were used. For the composite profile, a mesh with a global density of $4 \mathrm{~mm}$ was used. The overall number of finite elements (within the discrete model) was 7000 while the nodes 7242 (2000 elements of type S4R and 5000 of type R3D4).

The numerical simulations were mainly focused on the buckling behavior of the composite structure, with particular emphasis on the effect of the laminate layup configuration on the stability of the structure. The numerical models prepared, differed only in the lay-ups of the composite material, which were detailed in Section 2. In this paper, only numerical studies are presented, while further research will be the experimental verification of the prepared numerical models.

\section{NUMERICAL SIMULATION RESULTS}

This section will present the results of numerical simulations using the FEM. The result of the conducted research was the determination of buckling forms, together with the corresponding critical loads. The research results are presented in such a way that the result of the deformation form obtained in the critical state is shown for each lay-up of the composite material respectively: P1 - [0/45/-45/90], P2 - [0/90/0/90], P3 - [45/-45/90/0 $]_{\mathrm{s}}$ and P4 - [90/-45/45/0].

The results obtained are presented using the first form of buckling of the structure as an example. Based on the study, a particular behavior of thin-walled composite structures was observed under buckling analysis. Based on the obtained critical state results, it was observed that each configuration of the composite material layers affects the differential behavior of the composite structure. The form of buckling obtained for the structure with designation P1, was characterized by the occurrence of 3 half-waves, on each wall of the composite profile, in the longitudinal direction. The critical load, which occurred in this form of buckling was $\mathrm{P}_{\text {cr }}=7661.8 \mathrm{~N}$. For the $\mathrm{P} 2$ structure, it was observed that there were 4 half-waves on the composite profile walls in the longitudinal 


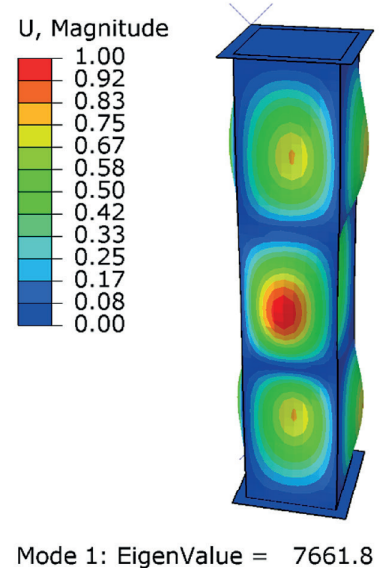

a)

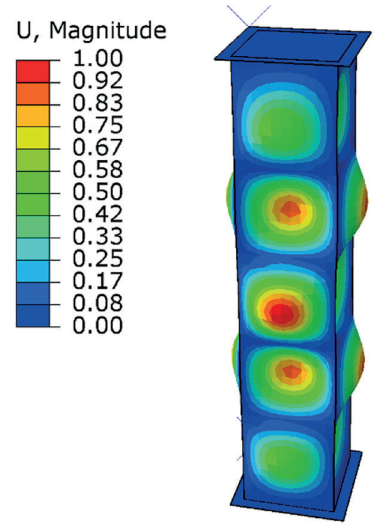

Mode 1: EigenValue $=10315$

c)

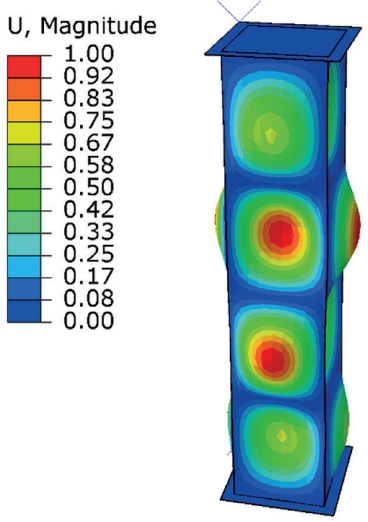

Mode 1: EigenValue $=6535.5$

b)

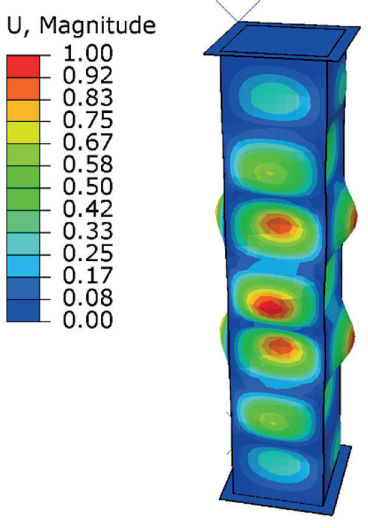

Mode 1: EigenValue $=7364.8$

d)

Fig. 4. Simulation results: a) P1 - specimen, b) P2 - specimen, c) P3 - specimen, d) P4 - specimen

direction of the column. The critical load which corresponded to the buckling form obtained was $\mathrm{P}_{\mathrm{cr}}=6535.5 \mathrm{~N}$. For structure P3, 5 half-waves were observed, which corresponded to a critical load of $\mathrm{P}_{\mathrm{cr}}=10315 \mathrm{~N}$. Structure P4 was characterized by the occurrence of 7 half-waves, while the critical load in this case was $\mathrm{P}_{\text {cr }}=7364.8 \mathrm{~N}$. In each of the analyzed cases, the occurrence of a local form of buckling was observed. It was observed that the maximum level of deformation, which is related to the highest recorded deflection of the structure, occurs in the middle part of the analyzed profiles, regardless of the arrangement of the composite material layers.

Additionally, within the qualitative assessment, it was noted that the use of each subsequent arrangement of composite layers, from P1 to $\mathrm{P} 4$, resulted in a change in the form of buckling, where an increase in the number of half-waves was registered, on the walls of the composite profile in the longitudinal direction of the structure. The increase in the number of half-waves from 3 - for the P1 structure, to 7 - for the P4 structure, did not have a direct impact on the increase of critical loads, and consequently on the stiffness of the structure. Based on the buckling tests, it was estimated that the structure with the P2 lay-up had the lowest critical load of $\mathrm{P}_{\text {cr }}=6535.5 \mathrm{~N}$, while the structure with the P3 lay-up showed a load with the highest value of $\mathrm{P}_{\mathrm{cr}}=10315 \mathrm{~N}$. Regarding the above, it was observed that structure P3 showed 1.58 times higher critical load than structure P2. As part of the critical state results, a very important conclusion can be derived. The highest value of the critical load occurring in the P3 structure is caused by the fact that the high stiffness is determined on the basis that the outer layers of the composite begin at an angle of 45 after which -45 degrees. The $\mathrm{P} 2$ structure is characterized by the occurrence of several 90-degree layers, where the fibers are arranged transversely to the compression direction, which reduces the stiffness of the composite structure, thus resulting in a significantly lower critical load than in the other cases.

Moreover, a preliminary analysis of the effect of mesh density on buckling results was conducted 


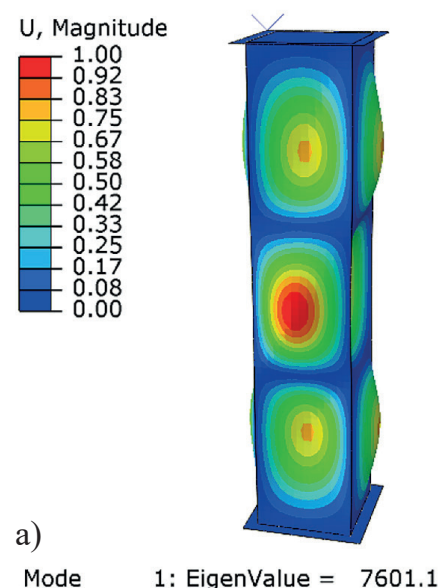

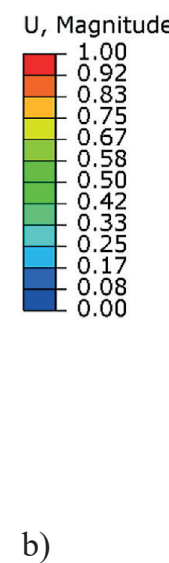

Mode

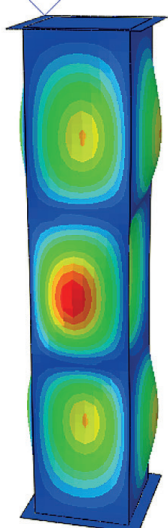

$1:$ EigenValue $=7661.8$

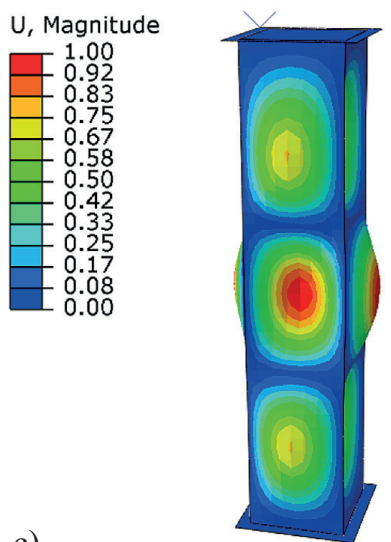

c)

Mode

$1:$ EigenValue $=7743.0$

Figure 5. Effect of mesh density on buckling results $-\mathrm{P} 1$ profile:

a) mesh - $3 \mathrm{~mm}, \mathrm{~b}) \mathrm{mesh}-4 \mathrm{~mm}$, c) mesh $-5 \mathrm{~mm}$

(based on the $\mathrm{P} 1$ profile). The base case, where the composite structure was described by a mesh density of $4 \mathrm{~mm}$, was compared with a case with a lower composite profile mesh density of $3 \mathrm{~mm}$ and a higher density of $5 \mathrm{~mm}$.

It was observed that both decreasing the mesh density (from 4 to $3 \mathrm{~mm}$ ) - Figure $5 \mathrm{a}$, and increasing (from 4 to $5 \mathrm{~mm}$ ) - Figure $5 \mathrm{c}$, has no significant effect on the stability of the structure. The buckling forms are almost identical, while a $+/-1 \mathrm{~mm}$ change in mesh density showed differences in critical load from the base case (Figure $5 b)$, at a range of about $1 \%$.

These observations, significantly contribute to the correct ability to design composite structures - laminates. Conducted numerical simulations will be the ground for further research in the field of nonlinear stability of the structure taking into account the behavior in the post-buckling state. In further studies, comparative analyses of the critical state for structures with other closed sections will be carried out, as well as analyses related to the failure of the composite material, under the influence of axial compressive load. Research presented in this paper, is a preliminary study carried out under the project of the National Science Centre, Poland (project No. 2021/41/B/ST8/00148).

\section{CONCLUSIONS}

A critical state analysis, using the FEM, has been carried out to provide a preliminary assessment of the stability of the structure. This study is a preliminary research for further scientific studies in the field of stability of thin-walled composite structures with closed sections. On the basis of the study, the following issues were observed:

- it is possible to determine the critical state for composite structures with closed sections using the finite element method within the framework of the linear eigenproblem solution;

- significant influence on the stability of composite structures with closed sections has the arrangement of composite material layers;

- the use of the arrangement of layers, where there is a predominance of layers at an angle of $+/-45$ degrees, especially in the outer layers, increases the critical load of the composite structure;

- a slight change in the mesh density of the composite structure has little effect on the buckling results.

\section{Acknowledgements}

The research was conducted under project No. 2021/41/B/ST8/00148 financed by the National Science Centre, Poland.

\section{REFERENCES}

1. Rozylo P., Teter A., Debski H., Wysmulski P., Falkowicz K. Experimental and Numerical Study of Buckling of Composite Profiles with Open Cross Section under Axial Compression. Appl. Compos. Mater. 2017; 24: 1251-1264.

2. Banat D., Mania R.J. Failure assessment of thinwalled FML profiles during buckling and postbuck- 
ling response. Compos B Eng; 2017; 112: 278-289.

3. Rozylo P., Wrzesinska K. Numerical analysis of the behavior of compressed thin-walled elements with holes. Adv. Sci. Technol. Res. J. 2016; 10(31): 199-206.

4. Turvey G.J., Zhang Y. A computational and experimental analysis of the buckling, postbuckling and initial failure of pultruded GRP columns. Compos. Struct. 2006; 84: 1527-1537.

5. Ascione F. Influence of initial geometric imperfections in the lateral buckling problem of thin walled pultruded GFRP I-profiles. Compos. Struct. 2014; 112: 85-99.

6. Teter A., Kolakowski Z. Buckling of thin-walled composite structures with intermediate stiffeners. Compos. Struct. 2005; 69(4): 421-428.

7. Rozylo P., Debski H., Kral J. Buckling and limit states of composite profiles with top-hat channel section subjected to axial compression. AIP Conference Proceedings. 2018; 1922: 080001.

8. Singer J., Arbocz J., Weller T. Buckling Experiments: Experimental Methods in Buckling of Thin-Walled Structure: Basic Concepts, Columns, Beams, and Plates; John Wiley and Sons Inc.: New York, NY, USA 2000, 1.

9. Li Z.M., Qiao P. Buckling and post buckling behaviour of shear deformable anisotropic laminated beams with initial geometric imperfections subjected to axial compression. Eng. Struct. 2015; 85: 277-292.

10. Paszkiewicz M., Kubiak T. Selected problems concerning determination of the buckling load of channel section beams and columns. Thin Walled Struct. 2015; 93: 112-121.

11. Debski H., Rozylo P., Teter A. Buckling and limit states of thin-walled composite columns under eccentric load. Thin-Walled Struct. 2020; 149: 106627.

12. Rozylo P. Stability and failure of compressed thinwalled composite columns using experimental tests and advanced numerical damage models. Int J Numer Methods Eng. 2021; 122: 5076-5099.

13. Rozylo P. Failure analysis of thin-walled composite structures using independent advanced damage models. Compos. Struct. 2021; 262: 113598.

14. Kolanu N.R., Raju G., Ramji M. A unified numerical approach for the simulation of intra and inter laminar damage evolution in stiffened CFRP panels under compression. Compos. B. Eng. 2020; 190: 107931.

15. Li W., Cai H., Li C., Wang K., Fang L. Progressive failure of laminated composites with a hole under compressive loading based on micro-mechanics. Adv. Compos. Mater. 2014; 23: 477-490.

16. Ribeiro M.L., Vandepitte D., Tita V. Damage model and progressive failure analyses for filament wound composite laminates. Appl. Compos. Mater. 2013; 20: 975-992.

17. Rozylo P., Wysmulski P. Failure analysis of thinwalled composite profiles subjected to axial compression using progressive failure analysis (PFA) and cohesive zone model (CZM). Compos. Struct. 2021; 262: 113597.

18. Fascetti A., Feo L., Nistic N., Penna R. Web-flange behavior of pultruded GFRP I beams: a lattice model for the interpretation of experimental results. Compos B Eng. 2016; 100: 257-269.

19. Wael F. Ragheb. Local buckling analysis of pultruded FRP structural shapes subjected to eccentric compression. Thin Walled Struct. 2010; 48: 709-717.

20. Nunes F., Correia M., Correia J.R., Silvestre N., Moreira A. Experimental and numerical study on the structural behaviour of eccentrically loaded GFRP columns. Thin Walled Struct. 2013; 72: 175-187.

21. Gliszczynski A., Kubiak T. Progressive failure analysis of thin-walled composite columns subjected to uniaxial compression. Compos. Struct. 2017; 169: 52-61.

22. Urbaniak M., Świniarski J., Czapski P., Kubiak T. Experimental investigations of thin-walled GFRP beams subjected to pure bending. Thin-Walled Struct. 2016; 107: 397-404.

23. Droździel M., Podolak P., Czapski P., Zgórniak P., Jakubczak P. Failure analysis of GFRP columns subjected to axial compression manufactured under various curing-process conditions. Compos. Struct. 2021; 262: 113342. 